\title{
Macrophage migration inhibitory factor facilitates production of CCL5 in astrocytes following rat spinal cord injury
}

Yue Zhou ${ }^{1,2+}$, Wei Guo ${ }^{3 \dagger}$, Zhenjie Zhu', Yuming Hu', Yingjie Wang ${ }^{2}$, Xuejie Zhang ${ }^{2}$, Wenjuan Wang ${ }^{2}$, Nan Du², Tiancheng Song ${ }^{2}$, Kaini Yang ${ }^{4}$, Zongyu Guan ${ }^{4}$, Yongjun Wang ${ }^{2^{*}}$ and Aisong Guo ${ }^{1 *}$

\begin{abstract}
Background: Astrocytes act as immune effector cells with the ability to produce a wide array of chemokines and cytokines in response to various stimuli. Macrophage migration inhibitory factor (MIF) is inducibly expressed in injured spinal cord contributing to excessive inflammation that affects motor functional recovery. Unknown is whether MIF can facilitate inflammatory responses through stimulating release of chemokines from astrocytes following spinal cord injury.

Methods: Following the establishment of the contusion spinal cord injury rat model, the correlation of chemokine (C-C motif) ligand 5 (CCL5) expression with that of MIF was assayed by Western blot, ELISA, and immunohistochemistry. Immunoprecipitation was used to detect MIF interaction with membrane CD74 receptor. Intracellular signal transduction of MIF/CD74 axis was analyzed by transcriptome sequencing of primary astrocytes and further validated by treatment of various inhibitors. The effects of CCL5 released by astrocytes on macrophage migration were performed by transwell migration assay. The post-injury locomotor functions were assessed using the Basso, Beattie, and Bresnahan (BBB) locomotor scale.

Results: The protein levels of chemokine CCL5/RANTES were remarkably increased in the astrocytes of rat injured spinal cord, in parallel with the expression of MIF. Treatment of MIF inhibitor 4-IPP in the lesion sites resulted in a significant decrease of CCL5 protein levels. In vitro study revealed MIF was capable of facilitating CCL5 production of astrocytes through interaction with CD74 membrane receptor, and knockdown of this receptor attenuated such effects. Production of CCL5 in astrocytes was significantly blocked by inhibitor of C-Jun N-terminal kinase, rather than by those of ERK and P38. Recombinant CCL5 protein was found to be more effective in promoting migration of M2- compared to M1-type macrophages.

Conclusion: Collectively, these data reveal a novel function of MIF in regulation of CCL5 release from astrocytes, which in turn favors for recruitment of inflammatory cells to the injured site of the spinal cord, in association with activation of excessive inflammation.
\end{abstract}

Keywords: MIF, CCL5, Spinal cord, Astrocyte, Inflammation, Chemokines

\footnotetext{
*Correspondence: wyjbs@ntu.edu.cn; 15851300188@163.com

${ }^{\dagger}$ Yue Zhou and Wei Guo contributed equally to this work.

${ }^{2}$ Key Laboratory of Neuroregeneration of Jiangsu and Ministry of Education,

Co-innovation Center of Neuroregeneration, Nantong University, Nantong

226001, People's Republic of China

1 Department of Rehabilitation Medicine, Affiliated Hospital of Nantong

University, Nantong 226001, People's Republic of China

Full list of author information is available at the end of the article
}

(c) The Author(s). 2018 Open Access This article is distributed under the terms of the Creative Commons Attribution 4.0 International License (http://creativecommons.org/licenses/by/4.0/), which permits unrestricted use, distribution, and

reproduction in any medium, provided you give appropriate credit to the original author(s) and the source, provide a link to the Creative Commons license, and indicate if changes were made. The Creative Commons Public Domain Dedication waiver (http://creativecommons.org/publicdomain/zero/1.0/) applies to the data made available in this article, unless otherwise stated. 


\section{Background}

The central nervous system (CNS) can activate innate immune responses by sensing pathogens or tissue damages [1]. Upon acute traumatic spinal cord injury, the resident immune and glial cells are rapidly motivated to release various cytokines and chemokines, which further induce leukocyte infiltration to the injury sites [2, 3]. Astrocytes are the most abundant glial cell contributing to the functional homeostasis of the healthy CNS. They can also receive and integrate information from synapses, other glial cells, and the blood vessels and as a consequence generate complex outputs that control the neural circuitry and coordinate it with the local microcirculation [4]. Astrocytes have been shown to participate in local inflammatory responses [5-8]. In the context of inflammatory or otherwise pathological conditions, the activated astrocytes proliferate and produce a wide variety of cytokines and chemokines, including CCL2 (monocyte chemotactic protein-1), CCL5 (RANTES), and CXCL8 (IL-8), which are associated with the recruitment of immune cells of alternative activation status [5, 9]. These recruited microglia/macrophages play either a pro-inflammatory (M1) or anti-inflammatory (M2) role as seen in a spinal cord injury model or neuroinflammatory diseases like multiple sclerosis (MS) [10]. Chemokine (C-C motif) ligand 5 (CCL5) may serve to amplify inflammatory responses by facilitating the recruitment of inflammatory cells into autoimmune lesions $[6,11$, 12]. As such, astrocyte-released cytokines and chemokines which contribute to inflammatory responses will inevitably exacerbate the neuropathological changes following CNS injury.

Macrophage migration inhibitory factor (MIF) is a pro-inflammatory cytokine produced by a variety of cells and tissues, including monocytes, the anterior pituitary gland, T-lymphocytes, hepatocytes, and keratinocytes $[13,14]$. MIF has been found to be constitutively or inducibly expressed in astrocytes, neurons, microglia, ependymal cells, and epithelial cells of the choroid plexus in the CNS [14-17]. Besides its roles of inducing neuronal death and activating inflammatory episodes in microglia, MIF is capable of promoting proliferation and inflammatory cytokine production of astrocytes [16, 18]. Deletion of MIF has been shown to promote functional recovery after compression-induced spinal cord injury [17], suggesting that MIF plays key roles in the neuropathogenesis of injured spinal cord. Astrocytes are the main sources of chemokines involved in recruitment of inflammatory cells; whether MIF is able to induce the release of chemokines from the cells remains unclear.

Astrocytes are endowed with the ability to secrete cytokines through expressing an array of receptors involved in innate immunity, such as Toll-like receptors and nucleotide-binding oligomerization domains [19, 20].
Also, the cells express CD74 surface receptor which can interact with MIF to elicit inflammatory responses after spinal cord injury (SCI) [18]. As MIF/CD74 axis has been found to activate intracellular MAPKs of astrocytes, an intermediate signaling essential for regulation of CCL5 and other chemokines [21, 22], MIF/CD74 axis is therefore postulated to mediate the production of CCL5 in astrocytes, which has been identified to promote inflammatory cell recruitment. In the present study, we analyzed the correlations between expression of MIF and CCL5 in the injured spinal cord of rat. We further investigated MIFinduced production of CCL5 in the astrocytes, as well as the underlying molecular mechanism. Our results have revealed that MIF affects pathological changes of the injured spinal cord through not only activation of astrocyte inflammatory responses, but also promoting release of chemokines.

\section{Methods \\ Animals}

Adult male Sprague-Dawley (SD) rats, weighing 180$220 \mathrm{~g}$, were provided by the Center of Experimental Animals, Nantong University. All animal care, breeding, and testing procedures were approved according to the Animal Care and Use Committee of Nantong University and the Jiangsu Province Animal Care Ethics Committee. All animals were housed in individual cages in a temperature and light/dark cycle controlled environment with free access to food and water.

\section{Establishment of the contusion $\mathrm{SCl}$ rat model}

The number of animals subjected to surgical treatment was calculated by six per experimental group in triplicate. The contusion SCI rat model was prepared as the previous description [23]. Briefly, rats were anesthetized with an intraperitoneal injection of $10 \%$ chloral hydrate (3 mg/kg). The fur was shaved from the surgical site and the skin was disinfected with chlorhexidine. A 15-mm midline skin incision was made to expose the vertebral column. After the spinal thoracic region was exposed by separation of the dorsal muscles to the side, the spinous processes of T8-T10 vertebrae were exposed. A laminectomy was performed at vertebral level T9, exposing the dorsal cord surface with the dura remaining intact. The exposed spinal cord segment (about $3 \mathrm{~mm}$ in length) received a 150-kilodyne spinal contusion injury using the IH-0400 Impactor (Precision Systems and Instrumentation) injury device. The impact rod was removed immediately, and the wound was irrigated. Muscles and incisions were sutured using silk threads. Postoperative care included butorphanol administration twice a day for a 5-day period, as well as vitamins, saline, and enrofloxacin twice a day for a 7-day period. Manual 
expression of the bladders was performed twice a day until animals recovered spontaneous voiding.

\section{Cell culture}

Astrocytes were prepared from the spinal cord of newborn Sprague-Dawley rats, 1-2 days after birth, and the astrocytes were isolated and cultured according to previously described methods [24]. Briefly, the cells were enzymatically dissociated using $0.25 \%$ trypsin (Gibco-BRL) for $6 \mathrm{~min}$ at $37^{\circ} \mathrm{C}$, and the suspension was then centrifuged at $1200 \mathrm{rpm}$ for $5 \mathrm{~min}$ and cultured in 1:1 Dulbecco's modified Eagle's medium to Ham's F-12 medium supplemented with $10 \%$ fetal bovine serum (FBS), $0.224 \% \mathrm{NaHCO}_{3}$, and $1 \%$ penicillin/streptomycin in the presence of $5 \% \mathrm{CO}_{2}$. A monolayer of astrocytes was obtained 12-14 days after the plating. Non-astrocytes were detached from the flasks by shaking and were removed by changing the medium. Third or fourth passage cells were rendered quiescent through incubation in the medium containing $0.5 \%$ FBS for 4 days prior to the experiments. Astrocyte phenotype was confirmed by cells exhibiting a characteristic morphology and positive staining for the astrocytic marker glial fibrillary acid protein (GFAP).

\section{Western blot}

Protein was extracted from cells with a buffer containing 1\% SDS, $100 \mathrm{mM}$ Tris- $\mathrm{HCl}, 1 \mathrm{mM}$ PMSF, and $0.1 \mathrm{mM}$ $\beta$-mercaptoethanol, following treatment with $0.5 \mu \mathrm{g} / \mathrm{ml}$ rat recombinant MIF (ProSpec) for $15 \mathrm{~min}, 30 \mathrm{~min}$, and $60 \mathrm{~min}$, respectively. Alternatively, protein was extracted from $1-\mathrm{cm}$ spinal segments of the injured site at 0 day, 1 day, 4 days, and 1 week following contusion $(n=8$ in each time point). Protein concentration of each specimen was detected by the Bradford method to maintain the same loads. Protein extracts were heat-denatured at $95{ }^{\circ} \mathrm{C}$ for $5 \mathrm{~min}$, electrophoretically separated on $10 \%$ SDS-PAGE, and transferred to PVDF membranes. The membranes were subjected to the reaction with a 1:1000 dilution of primary antibodies in TBS buffer at $4{ }^{\circ} \mathrm{C}$ overnight, followed by a reaction with the secondary antibody conjugated with goat anti-rabbit or goat anti-mouse HRP dilution 1:1000 (Santa Cruz) at room temperature for $2 \mathrm{~h}$. After the membrane was washed, the HRP activity was detected using an ECL kit. The image was scanned with a GS800 Densitometer Scanner (Bio-Rad), and the data were analyzed using PDQuest 7.2.0 software (Bio-Rad). $\beta$-actin (1:5000) was used as an internal control. The antibodies used in Western blot are as follows: MIF (Abcam); p65NFkB (Cell Signaling Technology, CST), p-ERK1/2, and ERK1/2 (CST); and CD74 (Biorbyt) and $\beta$-actin (Proteintech).

\section{ELISA}

Primary astrocytes were treated with $0-2.5 \mu \mathrm{g} / \mathrm{ml}$ rat recombinant MIF for $24 \mathrm{~h}$, or tissue samples of spinal segments were prepared as mentioned $(n=6$ in each time point). Cell supernatants were harvested, and cells were lysed in the buffer containing 1\% SDS, $100 \mathrm{mM}$ Tris- $\mathrm{HCl}$, $1 \mathrm{mM}$ PMSF, and $0.1 \mathrm{mM} \beta$-mercaptoethanol. The lysates were centrifuged at $12,000 \mathrm{~g}$ for $15 \mathrm{~min}$. Levels of CCL5 were assessed using the appropriate ELISA kits (BD Biosciences, R\&D Systems) according to the manufacturer's directions. Plates were read using a 96-well plate reader (Biotek Synergy2) at a 450-nm wavelength.

\section{Tissue immunohistochemistry}

The vertebra segments were harvested from six experimental models of each time point, post-fixed, and sectioned. Sections were allowed to incubate with monoclonal MIF antibody (1:200 dilution), rabbit anti-IBA-1 antibody (1:400 dilution, Wako), polyclonal rabbit anti-CCL5 antibody (1:200 dilution, novusbio), or monoclonal mouse anti-human GFAP antibody (1:400 dilution, Sigma) at $4{ }^{\circ} \mathrm{C}$ for $36 \mathrm{~h}$. The sections were further reacted with the FITClabeled secondary antibody goat anti-mouse IgG (1:400 dilution, Gibco) or the TRITC-labeled secondary antibody donkey anti-rabbit IgG (1:400 dilution, Gibco) at $4{ }^{\circ} \mathrm{C}$ overnight, followed by observation under a confocal laser scanning microscope (Leica, Heidelberg, Germany).

\section{Immunoprecipitation}

The primary astrocytes were washed twice with cold phosphate-buffered saline and then extracted with lysis buffer $(20 \mathrm{mM}$ Tris-HCl, pH 7.5, $150 \mathrm{mM} \mathrm{NaCl}, 1 \mathrm{mM}$ EDTA, $1 \mathrm{mM}$ EGTA, 1\% Triton X-100, $2.5 \mathrm{mM}$ sodium pyrophosphate, $1 \mathrm{mM} \beta$-glycerolphosphate, $1 \mathrm{mM} \mathrm{Na}_{3} \mathrm{VO}_{4}$, $1 \mathrm{mM}$ phenylmethylsulfonyl fluoride, and Roche Applied Science's complete protease inhibitors). Whole-cell extracts were centrifuged at $14,000 \mathrm{rpm}$ for $20 \mathrm{~min}$ to remove the debris. The proteins in the supernatant were measured using a Protein Assay Kit II (Bio-Rad). For immunoprecipitation analysis, $500 \mu \mathrm{g}$ of total cell lysates was precleared with protein A plus G-Sepharose before incubation with specific antibodies, followed by addition of protein A plus G-Sepharose. The precipitated proteins were resolved in $2 \times$ SDS-PAGE sample buffer and separated by electrophoresis on $10-12 \%$ SDS-PAGE. After being transferred onto a polyvinylidene difluoride membrane (Millipore Corp.), they were incubated with anti-MIF or anti-CD74 antibody and further with horseradish peroxidase-conjugated secondary antibody (Santa Cruz).

\section{Transwell migration assay}

Migration of RAW264.7 cells were measured using 6.5-mm transwell chambers with $8-\mu \mathrm{m}$ pores (Costar, Cambridge, MA) as described previously [25]. A total of 
$100 \mu \mathrm{l}$ of RAW264.7 cells $\left(2 \times 10^{5}\right.$ cells $\left./ \mathrm{ml}\right)$ was transferred into the top chamber of the transwells and allowed to migrate at $37{ }^{\circ} \mathrm{C}$ in $5 \% \mathrm{CO}_{2}$. Meanwhile, $600 \mu \mathrm{l}$ of astrocytes $\left(1 \times 10^{5}\right.$ cells $\left./ \mathrm{ml}\right)$ was seeded into the lower chambers. After migration for $48 \mathrm{~h}$, the upper surface of each membrane was cleaned with a cotton swab. Cells attached to the bottom surface of each membrane were stained with $0.1 \%$ crystal violet, imaged, and counted using a DMR inverted microscope (Leica Microsystems, Bensheim, Germany). Assays were performed in triplicate for three times. To determine the effect of CCL5 on astrocyte-stimulated RAW264.7 migration, astrocytes were stimulated with $0.5 \mu \mathrm{g} / \mathrm{ml}$ recombinant MIF following CCL 5 siRNA interference for $24 \mathrm{~h}$ prior to a transwell assay. For M2 macrophage transition, RAW264.7 cells were treated with or without $20 \mathrm{ng} / \mathrm{ml}$ rat recombinant IL-13 for 2 days.

\section{Sequencing of mRNA}

Total RNA of astrocytes following treatment with CD74siRNA [18] or scramble for $48 \mathrm{~h}$, and then with $2.0 \mu \mathrm{g} / \mathrm{ml}$ recombinant MIF for $12 \mathrm{~h}$ and $24 \mathrm{~h}$, respectively, was extracted using the mirVana miRNA Isolation Kit (Ambion, Austin, TX) according to the manufacturer's instructions. They were then selected by RNA Purification Beads (Illumina, San Diego, CA) and undergone library construction and RNA-seq analysis. The library was constructed by using the Illumina TruSeq RNA sample Prep Kit v2 and sequenced by the Illumina HiSeq-2000 for 50 cycles. High-quality reads that passed the Illumina quality filters were kept for the sequence analysis.

\section{Bioinformatics analysis}

Differentially expressed mRNA was designated in a criterion of greater than twofold or less than twofold change in comparison with control. Function of genes was annotated by Blastx against the NCBI database or the AGRIS database (https://agris-knowledgebase.org/) with $E$ value threshold of $10^{-5}$. Gene ontology (GO) classification was obtained by WEGO (http://wego. genomics.org.cn/) via GO id annotated by Perl and R program. Kyoto Encyclopedia of Genes and Genomes (KEGG) pathways were assigned to the sequences using KEGG Automatic Annotation Server (KAAS) online. For all heatmaps, genes were clustered by Jensen-Shannon divergence.

A reconstructed gene network was created using the Ingenuity Pathway Analysis (IPA) Software on the basis of differentially expressed genes (fold change $<0.5$ for downregulated genes at $12 \mathrm{~h}$ and $24 \mathrm{~h}$ following CD74 knockdown) to investigate their regulatory pathways and cellular functions [26].

\section{Behavioral tests}

The hindlimb locomotor function recovery was evaluated using the Basso, Beattie, and Bresnahan (BBB) locomotor scale as previously described [27], after MIF or CCL5 treatment on $0,7,14$, and 21 days after surgery. Three well-trained investigators who were blind to the study observed the behavior of rats for $5 \mathrm{~min}$. The BBB score ranged from 0 to 21 according to the rating scale. Every rat had a BBB score of 21 before surgery. The BBB score would become 0 to 1 after a successful SCI.

\section{Statistical analysis}

Statistical significance of differences between groups was analyzed by one-way analysis of variance (ANOVA) followed by Bonferroni's post hoc comparisons tests with SPSS 15.0 (SPSS, Chicago, IL, USA). Normality and homoscedasticity of the data were verified before any statistical analysis using Levene's test. Statistical significance was set at $P<0.05$.

\section{Results \\ MIF facilitated expression of chemokine CCL5 in the astrocytes of injured rat spinal cord}

To uncover the potential function of MIF in CCL5 expression, we firstly determined the protein levels of MIF and CCL5 in the contused spinal cord at different time points. Results revealed that CCL5 protein levels, assayed by ELISA, were synchronously increased with elevation of MIF assayed by Western blot (Fig. 1a-c). While treatment of $8 \mu \mathrm{l}$ of $100 \mathrm{mM}$ MIF inhibitor 4-IPP in the lesion site resulted in the remarkable reduction of CCL5 production (Fig. 1c). The data indicate that MIF efficiently regulates CCL5 production following SCI.

Next, we sought to understand whether MIF-induced CCL5 expression was astrocyte-related. Immunostaining showed that CCL5 was exclusively colocalized with GFAP-positive, rather than with NeuN-, IBA-1-, or Olig2-positive cells (Additional file 1). CCL5 production was significantly increased in the GFAP-positive cells at 4 days following SCI (Fig. 1d, e). Whereas injection of $8 \mu \mathrm{l} 4$-IPP $(100 \mathrm{mM})$ at the lesion site markedly decreased the expression of CCL5 in astrocytes (Fig. 1e). The results indicate that MIF is involved in regulation of CCL5 production in astrocytes after SCI.

\section{Expression of CCL5 was regulated by MIF/CD74 axis in astrocytes}

MIF has been shown to interact with CD74 surface receptor, which forms a receptor complex with CXCR2 and CXCR4 to elicit intracellular signaling $[28,29]$. To elucidate whether MIF/CD74 couple also exists in astrocytes, the rat astrocytes were firstly isolated and cultured with purity more than 95\% (Fig. 2a, b). Co-immunoprecipitation was then carried out using anti-His or anti-CD74 antibody. As 

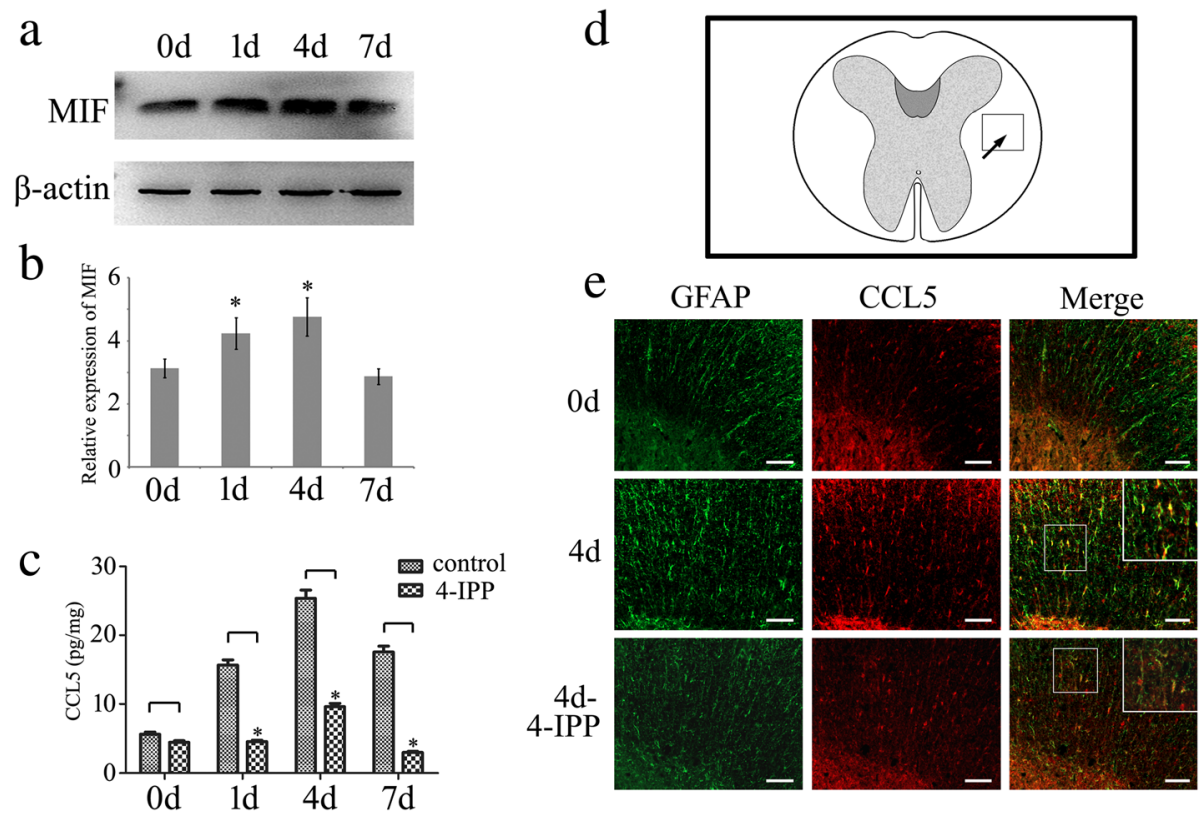

Fig. 1 Determination of MIF and CCL5 expression following spinal cord injury. a Western blot analysis of MIF expression following spinal cord contusion at $0 \mathrm{~d}, 1 \mathrm{~d}, 4 \mathrm{~d}$, and $7 \mathrm{~d}$, respectively. b Quantification data as shown in $\mathbf{a}$; quantities were normalized to endogenous $\beta$-actin. c CCL5 protein levels were assayed by ELISA for the injured cord at different time points with or without injection of $8 \mu$ l 4-IPP (100 mM) at the lesion sites. d Illustration of section sites showing immunostaining. e Immunostaining of CCL5 in the cross sections of rat contused spinal cord showed colocalization with GFAP-positive cells at $0 \mathrm{~d}$ and $4 \mathrm{~d}$, with or without injection of 4-IPP, respectively. The rectangle indicates region magnified. Error bars represent the standard deviation $(P<0.05)$. Scale bars, $100 \mu \mathrm{m}$

\section{a}

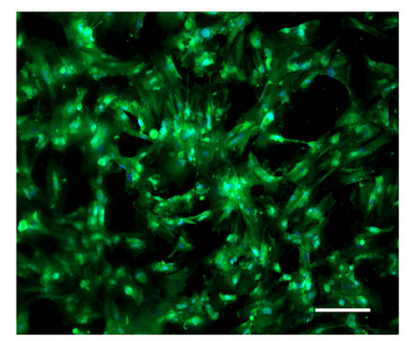

C

Input Input $\mathrm{A} / \mathrm{G} \quad \mathrm{A} / \mathrm{G} \quad \mathrm{A} / \mathrm{G} \quad \mathrm{A} / \mathrm{G} \quad \mathrm{A} / \mathrm{G}$

$\mathrm{M}$ control rMIF Ab-His control rMIF Ab-His Ab-His

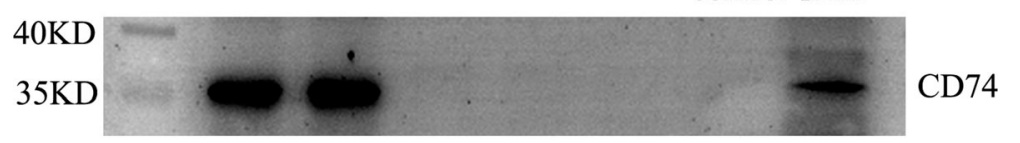

\section{$\begin{array}{llllll}\text { Input Input } & \mathrm{A} / \mathrm{G} & \mathrm{A} / \mathrm{G} & \mathrm{A} / \mathrm{G} & \mathrm{A} / \mathrm{G} & \mathrm{A} / \mathrm{G} \\ \text { control rMIF } & \mathrm{Ab}-\text { control } & \mathrm{rMIF} & \mathrm{Ab}-\mathrm{Ab}-\mathrm{cd} 74\end{array}$ control rMIF \\ control rMIF} control rMIF

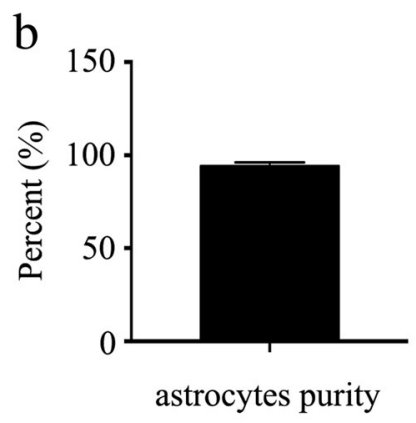

His

Fig. 2 Binding assay of MIF with CD74 receptor in the primary astrocytes. a Purified primary astrocytes stained with GFAP and Hoechst 33342. b Statistical analysis of primary astrocyte purity. c Immunoprecipitation using anti-His or anti-CD74 antibody and detection of the components of the rMIF- or CD74-associated complexes with anti-CD74 or anti-His antibody. M marker, A/G protein A/G magnetic beads. Scale bars, $50 \mu m$ 
shown in Fig. 2c, recombinant His-tagged MIF was present in the CD74-associated complexes immunoprecipitated with anti-CD74 antibody, so was CD74 in the His-associated complexes. The results indicate that MIF can bind with CD74 surface receptor of astrocytes.

To understand whether CCL5 expression is under regulation of MIF/CD74 axis, we performed transcriptome analysis on primary astrocytes interfered by effective CD74 siRNA or scramble for $48 \mathrm{~h}$ [18], followed by stimulation with $2.0 \mu \mathrm{g} / \mathrm{ml}$ recombinant MIF protein for 12 and $24 \mathrm{~h}$, respectively. A total of 456 and 255 differentially expressed genes (DEGs; siRNA versus scramble) were identified at the two time points, with defined criteria of $P<0.05$ and a greater than twofold or less than twofold change (Fig. 3a). We further integrated the DEGs and characterized 175 functional genes (Fig. 3a). KEGG pathway enrichment analysis of these integrated DEGs revealed that chemotaxis signaling, inflammatory responses, and related ERK1/2 cascades were included in the significantly enriched functional pathway (Fig. 3b). Such pathways account for 48 of all 175 DEGs.

To shed light on the mechanism of molecular changes following blockade of CD74, the Ingenuity Pathway Analysis (IPA) was performed for the DEGs integrated at 12 and $24 \mathrm{~h}$. The weight value of each gene in the network was calculated, representing the effect of MIF on the downstream targets. A reconstructed gene network showed that CCL5 and CCL12 with the highest weight value were highlighted as the important chemokines regulated by MIF/CD74 axis (Fig. 3c). As CCL12 has only been described in mice, we thus focus our attention on regulation of CCL5 [30].

All the genes displayed dynamic alteration following CD74 siRNA knockdown, as shown by the heatmap and cluster dendrogram (Fig. 4).

\section{MIF inhibitor attenuated CCL5 expression of astrocytes in vitro}

To substantiate inference drawn from transcriptome analysis, the primary astrocytes were stimulated with recombinant MIF protein at a concentration of $0-2.5 \mu \mathrm{g} / \mathrm{ml}$ for $24 \mathrm{~h}$, with or without addition of $100 \mu \mathrm{M} 4$-IPP. ELISA results showed that MIF was able to facilitate CCL5 production of astrocytes in a concentration-dependent manner. Treatment of astrocytes with $0.5 \mu \mathrm{g} / \mathrm{ml}$ MIF led to remarkable synthesis and secretion of CCL5, while addition of $100 \mu \mathrm{M}$ 4-IPP to the culture significantly reduced CCL5 protein levels in both supernatant and lysate (Fig. 5a, b). It

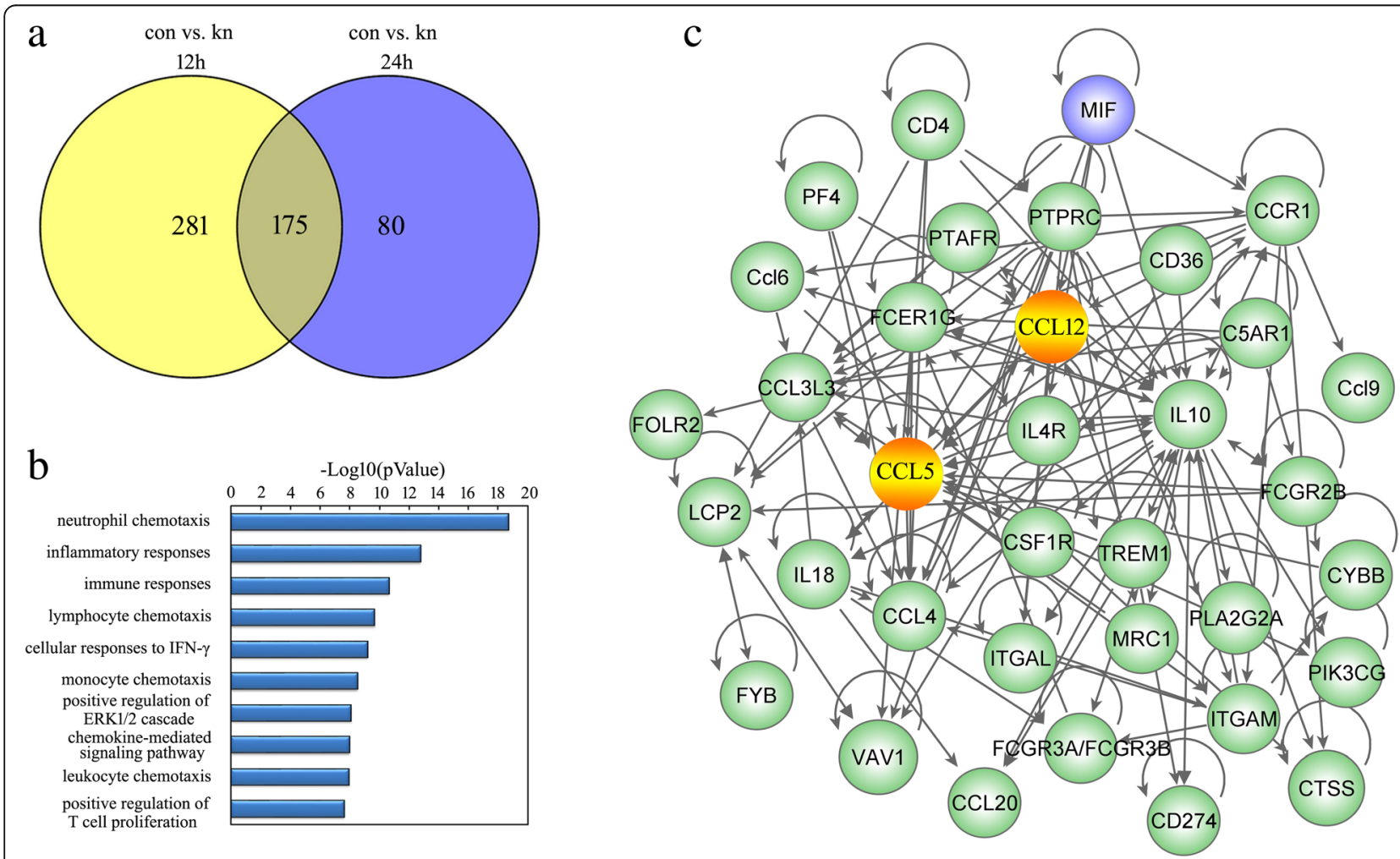

Fig. 3 Functional annotations of DEGs and the inferred gene network in the astrocytes. a Integration of DEGs following knockdown of CD74 receptor for $48 \mathrm{~h}$ and then treated with $2 \mu \mathrm{g} / \mathrm{ml}$ recombinant rat MIF at $12 \mathrm{~h}$ and $24 \mathrm{~h}$, respectively. b Most significantly enriched groups for the integrated DEGs relating to pathways. c A reconstructed gene network was created using the Ingenuity Pathway Analysis (IPA) Software on the basis of integrated DEGs 


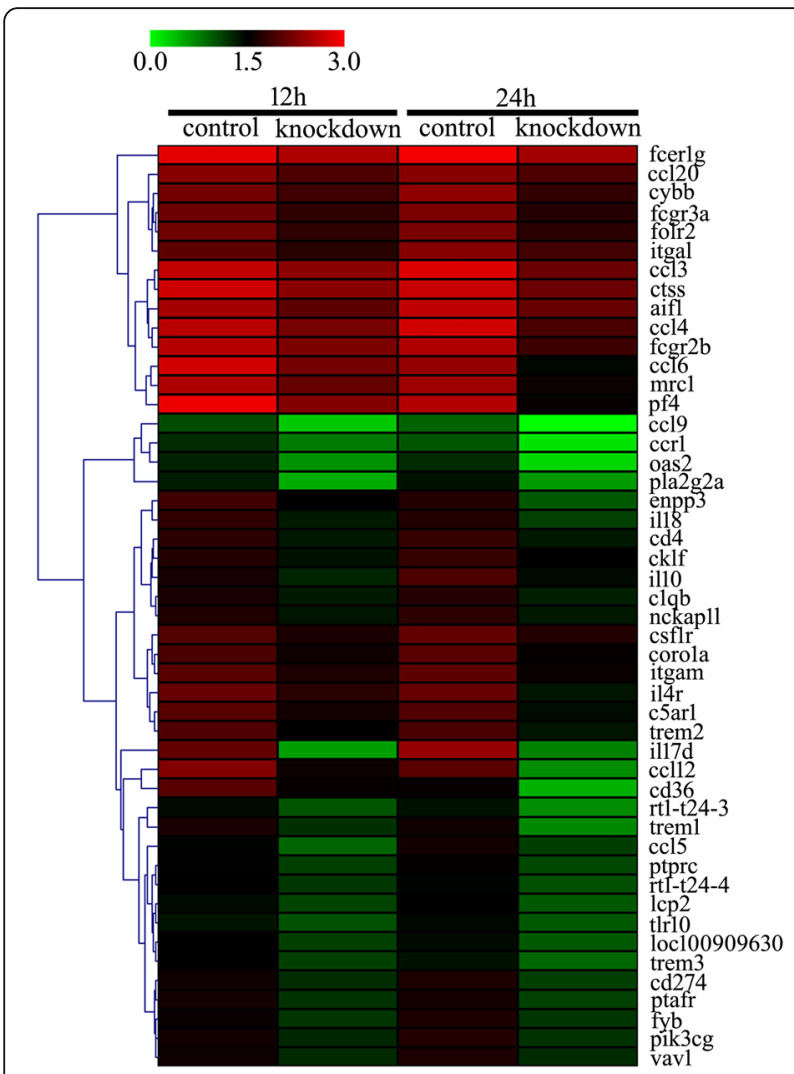

Fig. 4 Heatmap and cluster dendrogram of integrated DEGs following knockdown of CD74 receptor for $48 \mathrm{~h}$ and stimulated astrocytes with $2 \mu \mathrm{g} / \mathrm{ml}$ recombinant rat MIF for $12 \mathrm{~h}$ and $24 \mathrm{~h}$, respectively. The color scale shown at the top illustrates the relative expression level of the indicated mRNA across all samples: red denotes expression $>0$ and green denotes expression $<0$

was interesting to note that 4-IPP even decreased protein levels of CCL5 in lysate in the absence of MIF stimulation, probably involved in inhibition of endogenous CCL5 expression. These results indicate that MIF directly induces the CCL5 expression in astrocytes.

\section{MIF promoted CCL5 production of astrocytes through JNK signaling}

Several virus, cytokines, or natural chemicals are able to induce CCL5 production in immune cells or glial cells through mitogen-activated protein kinase (MAPK) and NFKB signaling pathways $[21,31,32]$. To clarify the relevant pathway through which MIF facilitates CCL5 production of astrocytes, we interfered with the signal pathway through knockdown of CD74 receptor. The siRNA oligonucleotide (siRNA2) with nearly $60 \%$ knockdown efficiency of CD74 was chosen for the next experiments (Fig. 6a). CD74 receptor of astrocyte was knocked down by siRNA2 for $48 \mathrm{~h}$, followed by the cell treatment with $0.5 \mu \mathrm{g} / \mathrm{ml}$ recombinant MIF protein for $15 \mathrm{~min}$, $30 \mathrm{~min}$, and $60 \mathrm{~min}$, respectively. Determination of ERK,
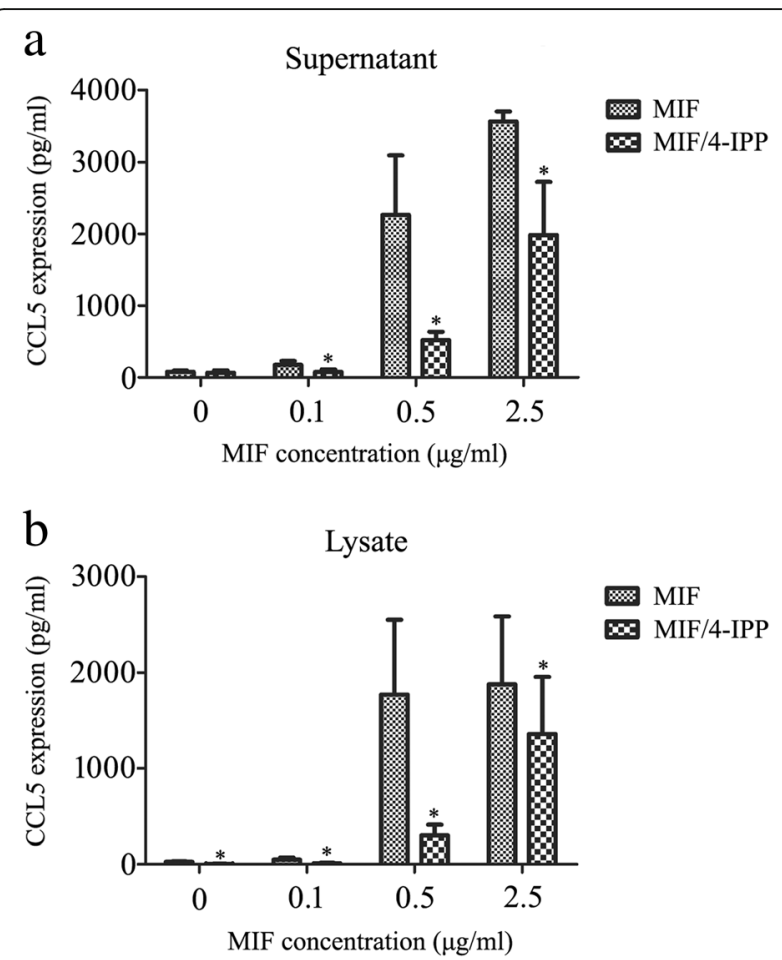

Fig. 5 Examination of CCL5 production in astrocytes following stimuli with gradient recombinant MIF in the presence of 4-IPP. Cell supernatants (a) and lysates (b) were tested by ELISA for the chemokine CCL5, following astrocyte treatment with $0-2.5 \mu \mathrm{g} / \mathrm{ml}$ recombinant MIF for $24 \mathrm{~h}$ in the presence of $100 \mu \mathrm{M} 4-I P P$.

Experiments were performed in triplicates. Error bars represent the standard deviation $(P<0.05)$

P38, and c-Jun N-terminal kinase (JNK) phosphorylation demonstrated that the phosphorylated level of these kinases and NFkB activity were significantly reduced in astrocytes (Fig. 6b, c). However, CCL5 production in the cells stimulated with recombinant MIF for $24 \mathrm{~h}$ was exclusively attenuated by treatment of JNK (SP600125), rather than by ERK (PD98059) or P38 (SB203580) inhibitor (Fig. 6d). These data indicate that MIF induces CCL5 production of astrocytes through JNK signaling.

\section{CCL5 primarily potentiated migration of IL-13-treated macrophages}

Chemokines are known to be essential for macrophage migration towards the site of injury [33]. To elucidate chemotactic function of astrocyte-released CCL5, we performed transwell assay to observe migration of macrophage RAW 264.7 cells in the presence of astrocytes with or without siRNA knockdown of CCL5 expression (Fig. 7a). Of three siRNA oligonucleotides, siRNA1 with a 72\% CCL5 knockdown efficiency was selected (Fig. 7b). Astrocytes were stimulated with $0.5 \mu \mathrm{g} / \mathrm{ml}$ recombinant MIF following CCL5 siRNA1 interference for $24 \mathrm{~h}$ prior to macrophage migration for $48 \mathrm{~h}$. Addition of recombinant MIF promoted 


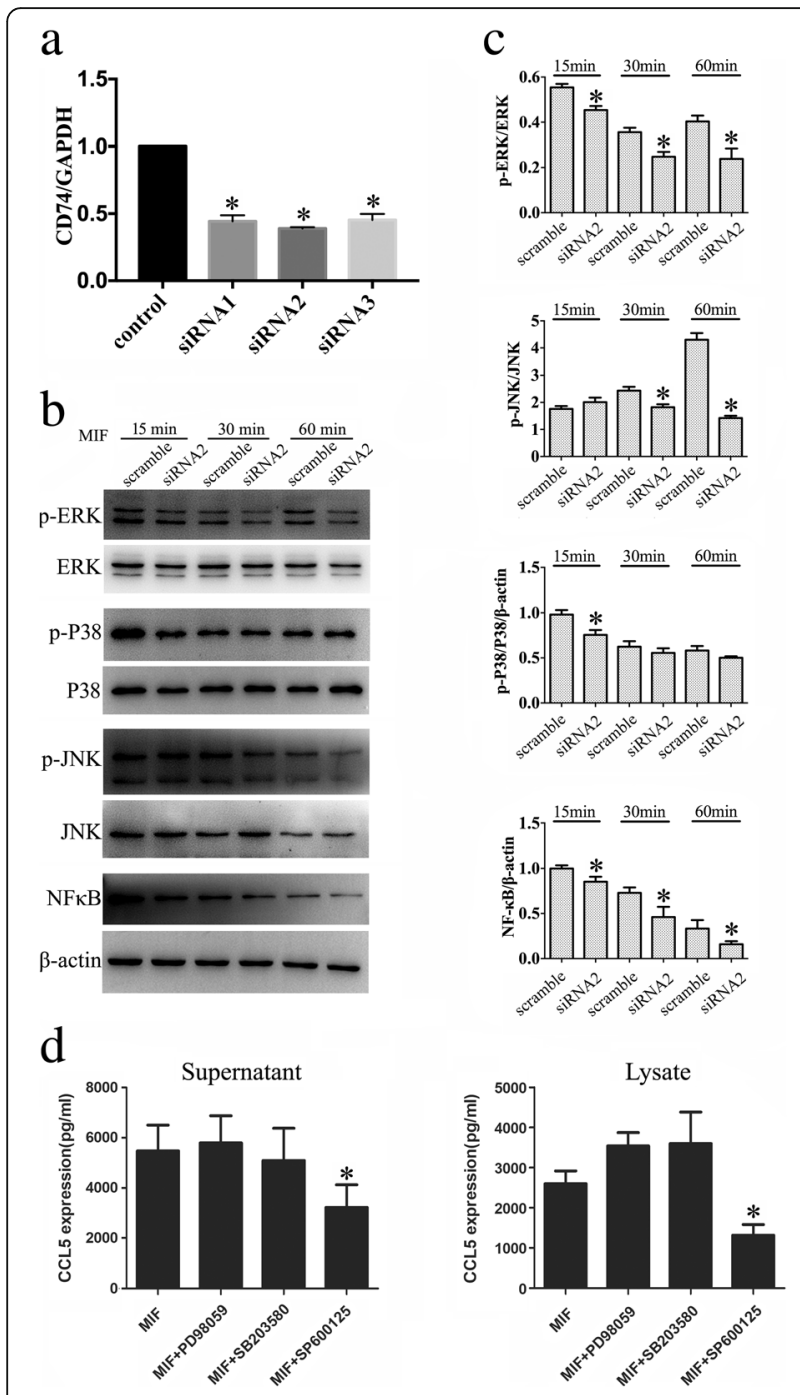

Fig. 6 Determination of intracellular signaling associated with regulation of CCL5 expression. a Interference efficiency of three siRNA oligonucleotides for CD74 was measured by RT-PCR, and siRNA2 was used for the knockdown experiments. $\mathbf{b}$ Western blot analysis of pERK, p-P38, pJNK, and p65NFkB following astrocytes treated with siRNA oligonucleotides or scramble for $48 \mathrm{~h}$ and then with $2 \mu \mathrm{g} / \mathrm{ml}$ recombinant MIF for $15 \mathrm{~min}, 30 \mathrm{~min}$, and 60 min, respectively. c Quantification data as shown in a. d Cell supernatants and lysates were tested by ELISA for the production of CCL5 following astrocyte treatment with inhibitor of ERK (PD98059), P38 (SB203580), or JNK (SP600125).

Experiments were performed in triplicates. Error bars represent the standard deviation $(P<0.05)$

a moderate migration of the unmodified macrophages, and such effect could be slightly attenuated by CCL 5 siRNA1 interference, suggesting other factors in action (Fig. 7c, d). However, when the macrophages were incubated in $20 \mathrm{ng} /$ $\mathrm{ml}$ recombinant rat IL-13 protein for 2 days, a transition from M1- to M2-phenotype identified by iNOS and Arginase1 expression [34], MIF was found to significantly facilitate the migration of these IL-13-modified cells (Fig. 7c-e).
CCL5 knockdown of astrocytes remarkably reduced migratory cell numbers (Fig. 7c, d). The data indicate that CCL5 produced by astrocytes is primarily involved in promoting migration of M2 macrophages.

To observe the effects of MIF-induced CCL5 on migration of microglia in vivo, we detected the temporal distribution of microglia following spinal cord injury. Immunostaining with IBA-1 antibody displayed that SCI resulted in significant accumulation of microglia in the injured cord, with a peak at 4 days (Fig. 8a, c). Injection of $8 \mu \mathrm{l}$ of $100 \mu \mathrm{g} / \mathrm{ml}$ recombinant MIF or $4 \mu \mathrm{l}$ of $100 \mu \mathrm{g} /$ $\mathrm{ml}$ recombinant CCL5 protein at the lesion site aggravated the amounts of IBA-1-positive cells. However, treatment with $8 \mu \mathrm{l}$ of $100 \mathrm{mM}$ 4-IPP resulted in a significant reduction of microglia migration (Fig. 8a-e).

To assess the influences of MIF or CCL5 on the functional recovery, $\mathrm{BBB}$ scores were measured during 3 weeks after the spinal cord injury. Injection of $8 \mu \mathrm{l}$ of $100 \mu \mathrm{g} / \mathrm{ml} \mathrm{recombinant} \mathrm{MIF} \mathrm{or} 4 \mu \mathrm{l}$ of $100 \mu \mathrm{g} / \mathrm{ml} \mathrm{re-}$ combinant CCL5 significantly aggravated the hindlimb motor function compared with the vehicle. However, treatment of 4-IPP demonstrated a significant improvement (Fig. 8f). The results indicate that MIF-induced CCL5 release from astrocytes is sufficient to potentiate migration of microglia in the injured spinal cord, which is involved in the neuropathogenesis.

\section{Discussion}

Emerging evidence has shown that MIF plays a role as a neuroimmuno-modulator in the CNS. Multiple cell types in CNS express this protein, such as microglia, fibroblasts, pituitary cells, endothelial cells, neurons, and neural stem cell progenitors [35]. Aberrant expression of MIF has shown to result in several pathological diseases of the CNS including Alzheimer's disease, autism spectrum disorders, encephalomyelitis, and tumorigenesis [35-38]. In the acute phase of spinal cord injury, MIF contributes to neuropathological impairments through promoting neuronal death and inflammatory activation [14, 16]. It has been thought that microglia and other leukocytes are main resources of inflammatory cytokines in response to MIF stimuli $[13,39]$. However, inflammatory signal pathway in astrocytes can also be activated by MIF through phosphorylation of ERK [18]. Here, we revealed a novel role of MIF in facilitating CCL5 production of astrocytes through activation of JNK, suggesting that MIF-induced releases of cytokines and chemokines are associated with multiple intracellular signals. Previous reports have shown that M1 and M2 macrophages populate the injury site with relatively equal distribution within the first week after SCI [40, 41]. MIF-induced CCL5 release from astrocytes is primarily implicated in the cell events of M2 macrophages.

MIF regulates distinct intracellular signaling in a cell type-dependent way. This factor has been shown to interact 
a
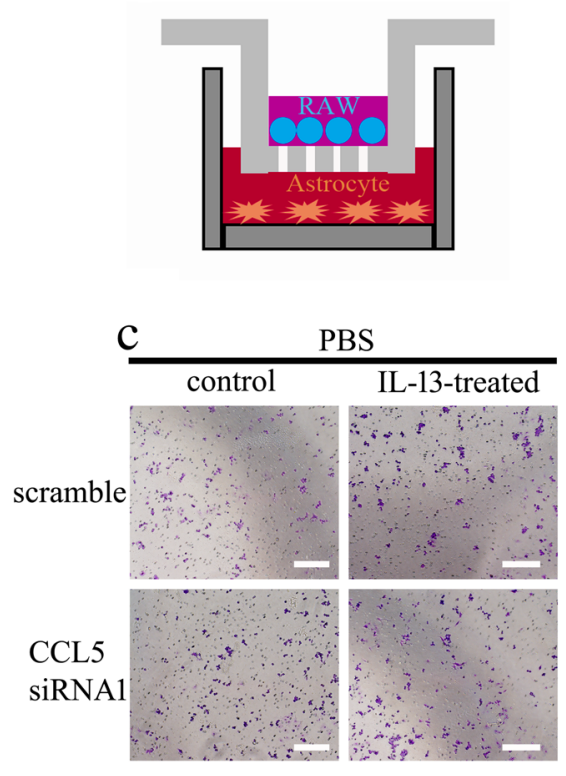

d

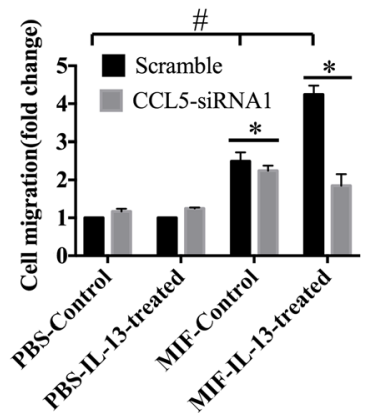

b

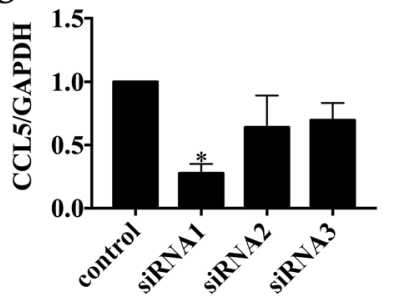

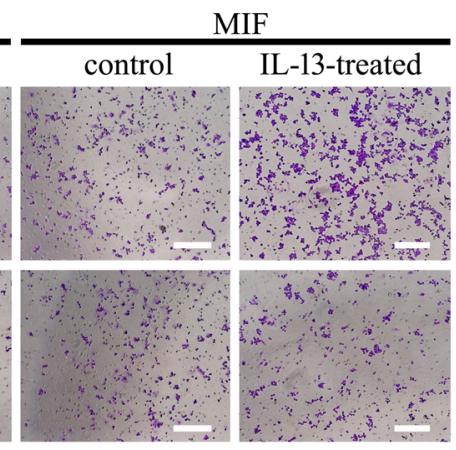

e
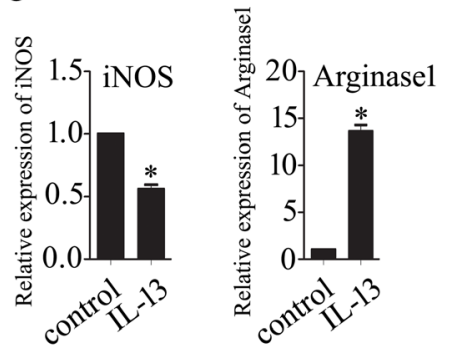

Fig. 7 Effects of CCL5 on macrophage migration in vitro. a Transwell assay using cell co-culture model. b Interference efficiency of three siRNA oligonucleotides for CCL5 was measured by RT-PCR, and siRNA1 was used for the knockdown experiments. c Migration assay of macrophages co-cultured with astrocytes with or without knockdown of CCL5. Astrocytes were stimulated with $0.5 \mu \mathrm{g} / \mathrm{ml}$ recombinant MIF following CCL5 siRNA interference for $24 \mathrm{~h}$ prior to macrophage migration for $48 \mathrm{~h}$. For a transition of macrophages from M1- to M2-phenotype, the cells were incubated in $20 \mathrm{ng} / \mathrm{ml}$ recombinant rat $\mathrm{IL}-13$ protein for 2 days. d Quantification data as shown in c. e The expression of M1 and M2 macrophage markers, iNOS and Arginase1, was determined by RT-PCR. Quantities were normalized to endogenous $\beta$-actin. Error bars represent the standard deviation. ${ }^{*} P<0.05,{ }^{\#} P<0.05$. Scale bars, $100 \mu \mathrm{m}$

with CD74 receptor on macrophages, astrocytes, fibroblasts, tumor cells, or B lymphocytes, resulting in sustained activation of ERK1/2 kinase that brings in various effects $[13,18,42]$. Activation of MIF on JNK signaling has been identified in fibroblasts and $\mathrm{T}$ cell lines, in which phosphorylation of JNK is regulated by kinases PI3K and SRC [43]. In the $\mathrm{CD} 11 \mathrm{~b}^{+} \mathrm{Gr}-1^{+}$myeloid cells, MIF is capable of potentiating chemotaxis, differentiation, and pro-angiogenesis through activation of p38/MAPK and PI3K/AKT signal pathways [44]. In the present study, we demonstrated that MIF/CD74 axis was able to regulate activities of ERK, P38, and JNK in astrocytes, suggesting a multifunctionality of MIF on astrocytes.

CCL5 induces the migration and recruitment of a wide variety of cells including T cells, dendritic cells, NK cells, eosinophils, basophils, mast cells, and endothelial progenitor cells $[9,45]$. Interestingly, its effects on chemotaxis of macrophages are found to have tissue specificity. For examples, CCL5 is involved in recruitment and survival of macrophages in human adipose tissue [46] and in accumulation of macrophage in the kidney, liver, and peripheral nervous tissues [47-49]. In the CNS, however, the role of CCL5 in recruitment of inflammatory cells is controversial. In the hippocampi of mice, CCL5 has been shown to be not critical for accumulation of microglia [2]. We revealed that CCL5 primarily facilitates migration of IL-13-incubated macrophages, in consistency with that of IL-4-treated M2 macrophages [10]. The discrepancy may be attributed to the distinct phenotypes of microglia, either a greater recruitment of monocyte-derived macrophages in 


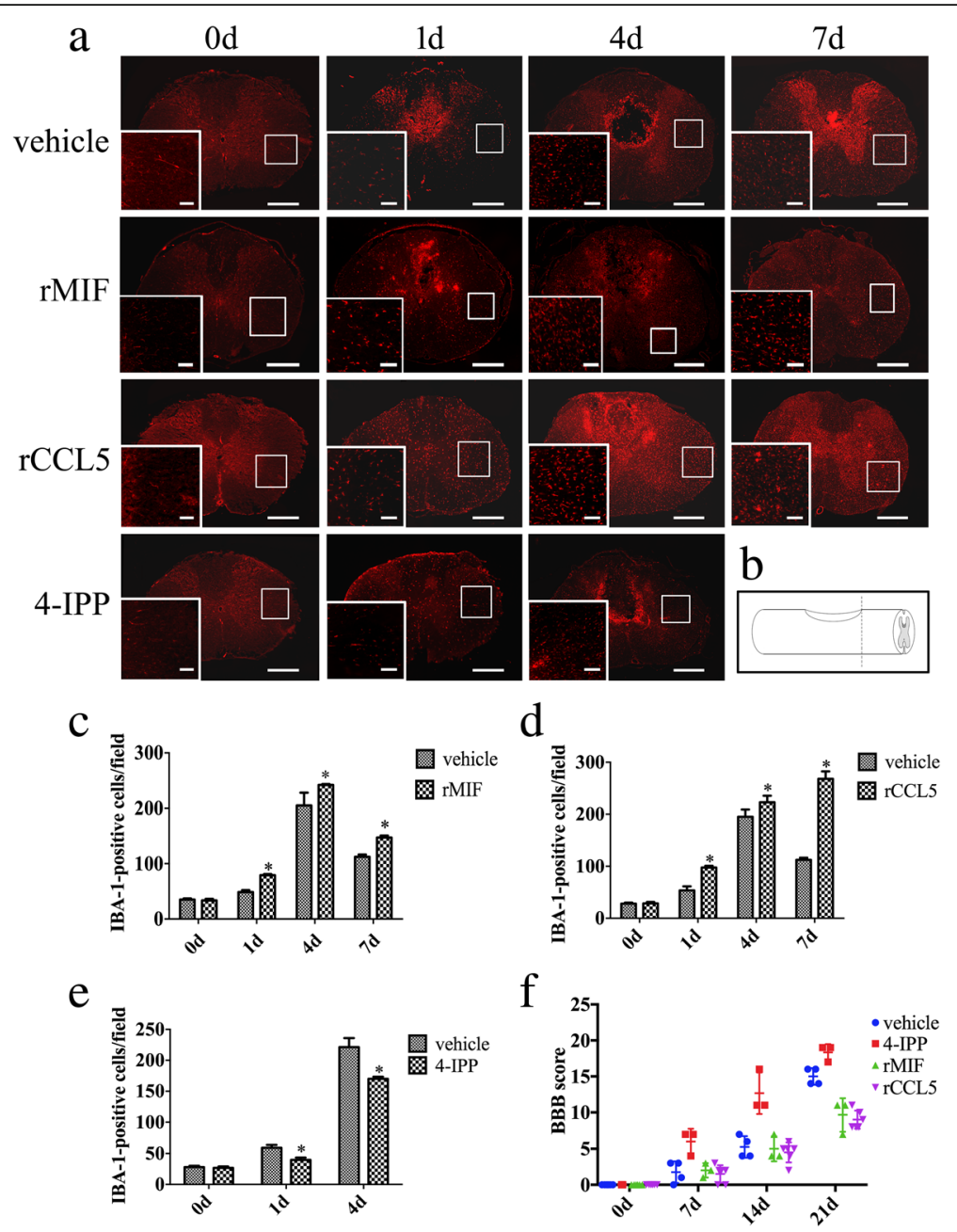

Fig. 8 Immunostaining of microglia after rat spinal cord injury. a Immunostaining of IBA-1-positive cells following spinal cord contusion at 0d, 1d, 4d, and $7 \mathrm{~d}$, following injection of $8 \mu \mathrm{l}$ of $100 \mu \mathrm{g} / \mathrm{ml}$ recombinant MIF, $4 \mu \mathrm{l}$ of $100 \mu \mathrm{g} / \mathrm{ml}$ recombinant CCL5, or $8 \mu \mathrm{l}$ of $100 \mathrm{mM}$ 4-IPP, respectively. The rectangle indicates region magnified. $\mathbf{b}$ Illustration of section sites for immunostaining in the contused cord. $\mathbf{c}-\mathbf{e}$ Statistic analysis of IBA-1-positive cells in $\mathbf{a}$ from 15 fields each. $\mathbf{f}$ BBB scores for hindlimb motor function in each group at different time points. Six rats/group were evaluated at $0 d$ after injury, and four rats in the vehicle-treated group and three rats in the 4-IPP- or rMIF-treated group were evaluated from 7 days onwards due to sacrifice for immunostainings following significant difference $(n=3-6)$. Error bars represent the standard deviation $(P<0.05)$. Scale bars, $500 \mu m$ in section, and $100 \mu \mathrm{m}$ in magnification

SCI or the alternative activation status stimulated by specific milieu [10, 50]. These results indicate that CCL5 alternatively facilitates accumulation of macrophages, depending on the cell subtype.

CCL5 is inducibly produced by invading pathogens or proinflammatory cytokines through activation of intracellular signals in a cell-specific manner $[9,31]$. HIV-1 induces CCL5 primarily by transcriptional activation, while bacterial lipopolysaccharide (LPS) induces CCL5 in microglia via activation of TLR4 receptor [51]. Cytokine IL-1 is able to induce expression of CCL5 in astrocytes through phosphorylation of P38 or JNK, but not of ERK [31]. In the present study, we displayed that MIF induced CCL5 production in astrocytes through activation of JNK signaling. These results indicate that the regulatory mechanism of CCL5 expression is differential in different cell types.

\section{Conclusions}

Protein levels of MIF were increased in response to SCI, which interacted with $\mathrm{CD} 74$ receptor of astrocytes to promote CCL5 production through activation of JNK. CCL5 in turn facilitated migration of macrophages to the lesion site, which affected repair of injured spinal cord.

\section{Additional file}

Additional file 1: Figure S1. Determination of CCL5 colocalization with NeuN-, IBA-1-, or Olig2-positive cells following spinal cord contusion at 4 days. (PDF $397 \mathrm{~kb}$ ) 


\section{Abbreviations}

ANOVA: Analysis of variance; MIF: Macrophage migration inhibitory factor: CCL5: Chemokine (C-C motif) ligand 5; PBS: Phosphate-buffered saline; MS: Multiple sclerosis; SCl: Spinal cord injury; GFAP: Glial fibrillary acid protein; ELISA: Enzyme-linked immunosorbent assay; KEGG: Kyoto Encyclopedia of Genes and Genomes; IPA: Ingenuity Pathway Analysis; DEGs: Differentially expressed genes

\section{Funding}

This study was supported by the the National Key Research and Development Program of China (2018YFC1105603), and the National Natural Science Foundation of China (No. 31471011; 31640042; 31871211).

\section{Availability of data and materials}

The datasets used and/or analyzed during the current study are available from the corresponding author on reasonable request.

\section{Authors' contributions}

YjunW and AG designed this work. YjunW wrote the paper. YZ, YjunW, and WG performed the experiments. YZ, YjunW, WG, AG, ZZ, YH, YjieW, XZ, WW $N D, K Y, Z G$, and TS analyzed the data. AG joined discussions. All authors have approved the final version of the manuscript and have agreed to be accountable for all aspects of the work regarding questions related to the accuracy or integrity of any part of the work.

\section{Ethics approva}

All animal experiments were approved by the Animal Care and Use Committee of Nantong University and the Jiangsu Province Animal Care Ethics Committee.

\section{Consent for publication}

Not applicable.

\section{Competing interests}

The authors declare that they have no competing interests.

\section{Publisher's Note}

Springer Nature remains neutral with regard to jurisdictional claims in published maps and institutional affiliations.

\section{Author details}

'Department of Rehabilitation Medicine, Affiliated Hospital of Nantong University, Nantong 226001, People's Republic of China. ${ }^{2}$ Key Laboratory of Neuroregeneration of Jiangsu and Ministry of Education, Co-innovation Center of Neuroregeneration, Nantong University, Nantong 226001, People's Republic of China. ${ }^{3}$ School of Basic Medical Sciences, Nanjing Medical University, Nanjing, People's Republic of China. ${ }^{4}$ Medical College, Nantong University, Nantong 226001, People's Republic of China.

\section{Received: 29 April 2018 Accepted: 29 August 2018}

\section{Published online: 04 September 2018}

\section{References}

1. Gadani SP, Walsh JT, Lukens JR, Kipnis J. Dealing with danger in the CNS the response of the immune system to injury. Neuron. 2015:87:47-62.

2. Babcock AA, Kuziel WA, Rivest $\mathrm{S}$, Owens T. Chemokine expression by glial cells directs leukocytes to sites of axonal injury in the CNS. J Neurosci. 2003; 23:7922-30.

3. Hausmann ON. Post-traumatic inflammation following spinal cord injury. Spinal Cord. 2003;41:369-78.

4. Rossi D. Astrocyte physiopathology: at the crossroads of intercellular networking, inflammation and cell death. Prog Neurobiol. 2015;130:86-120.

5. Luo Y, Berman MA, Zhai Q, Fischer FR, Abromson-Leeman SR, Zhang Y, Kuziel WA, Gerard C, Dorf ME. RANTES stimulates inflammatory cascades and receptor modulation in murine astrocytes. Glia. 2002;39:19-30.

6. Meeuwsen S, Persoon-Deen C, Bsibsi M, Ravid R, van Noort JM. Cytokine, chemokine and growth factor gene profiling of cultured human astrocytes after exposure to proinflammatory stimuli. Glia. 2003:43:243-53.

7. Carpentier PA, Begolka WS, Olson JK, Elhofy A, Karpus WJ, Miller SD. Differential activation of astrocytes by innate and adaptive immune stimuli. Glia. 2005;49:360-74.
8. Falsig J, Porzgen P, Lund S, Schrattenholz A, Leist M. The inflammatory transcriptome of reactive murine astrocytes and implications for their innate immune function. J Neurochem. 2006:96:893-907.

9. Marques RE, Guabiraba R, Russo RC, Teixeira MM. Targeting CCL5 in inflammation. Expert Opin Ther Targets. 2013;17:1439-60.

10. Vogel DY, Heijnen PD, Breur M, de Vries HE, Tool AT, Amor S, Dijkstra CD. Macrophages migrate in an activation-dependent manner to chemokines involved in neuroinflammation. J Neuroinflammation. 2014;11:23.

11. Glabinski AR, Tuohy VK, Ransohoff RM. Expression of chemokines RANTES, MIP-1alpha and GRO-alpha correlates with inflammation in acute experimental autoimmune encephalomyelitis. Neuroimmunomodulation. 1998:5:166-71.

12. Oh JW, Schwiebert LM, Benveniste EN. Cytokine regulation of CC and CXC chemokine expression by human astrocytes. J Neuro-Oncol. 1999;5:82-94.

13. Calandra T, Roger T. Macrophage migration inhibitory factor: a regulator of innate immunity. Nat Rev Immunol. 2003;3:791-800.

14. Chalimoniuk M, King-Pospisil K, Metz CN, Toborek M. Macrophage migration inhibitory factor induces cell death and decreases neuronal nitric oxide expression in spinal cord neurons. Neuroscience. 2006:139:1117-28.

15. Ogata A, Nishihira J, Suzuki T, Nagashima K, Tashiro K. Identification of macrophage migration inhibitory factor mRNA expression in neural cells of the rat brain by in situ hybridization. Neurosci Lett. 1998;246:173-7.

16. Koda M, Nishio Y, Hashimoto M, Kamada T, Koshizuka S, Yoshinaga K Onodera S, Nishihira J, Moriya H, Yamazaki M. Up-regulation of macrophage migration-inhibitory factor expression after compression-induced spinal cord injury in rats. Acta Neuropathol. 2004;108:31-6.

17. Nishio Y, Koda M, Hashimoto M, Kamada T, Koshizuka S, Yoshinaga K, Onodera S, Nishihira J, Okawa A, Yamazaki M. Deletion of macrophage migration inhibitory factor attenuates neuronal death and promotes functional recovery after compression-induced spinal cord injury in mice. Acta Neuropathol. 2009;117:321-8.

18. Su Y, Wang Y, Zhou Y, Zhu Z, Zhang Q, Zhang X, Wang W, Gu X, Guo A Wang $Y$. Macrophage migration inhibitory factor activates inflammatory responses of astrocytes through interaction with CD74 receptor. Oncotarget. 2017:8:2719-30.

19. Dong Y, Benveniste EN. Immune function of astrocytes. Glia. 2001:36:180-90.

20. Farina C, Aloisi F, Meinl E. Astrocytes are active players in cerebral innate immunity. Trends Immunol. 2007:28:138-45.

21. Lin MS, Hung KS, Chiu WT, Sun YY, Tsai SH, Lin JW, Lee YH. Curcumin enhances neuronal survival in N-methyl-d-aspartic acid toxicity by inducing RANTES expression in astrocytes via PI-3K and MAPK signaling pathways. Prog Neuro-Psychopharmacol Biol Psychiatry. 2011;35:931-8.

22. Gangwani MR, Noel RJ Jr, Shah A, Rivera-Amill V, Kumar A. Human immunodeficiency virus type 1 viral protein R (Vpr) induces CCL5 expression in astrocytes via PI3K and MAPK signaling pathways. J Neuroinflammation. 2013;10:136.

23. Chehrehasa F, Cobcroft M, Young YW, Mackay-Sim A, Goss B. An acute growth factor treatment that preserves function after spinal cord contusion injury. J Neurotrauma. 2014:31:1807-13.

24. Liu J, Du L. PERK pathway is involved in oxygen-glucose-serum deprivationinduced NF-kB activation via ROS generation in spinal cord astrocytes. Biochem Biophys Res Commun. 2015;467:197-203.

25. Zhao Y, Wang Y, Gong J, Yang L, Niu C, Ni X, Wang Y, Peng S, Gu X, Sun C, Yang $Y$. Chitosan degradation products facilitate peripheral nerve regeneration by improving macrophage-constructed microenvironments. Biomaterials. 2017;134:64-77.

26. Kramer A, Green J, Pollard J Jr, Tugendreich S. Causal analysis approaches in Ingenuity Pathway Analysis. Bioinformatics. 2014;30:523-30.

27. Basso DM, Beattie MS, Bresnahan JC. A sensitive and reliable locomotor rating scale for open field testing in rats. J Neurotrauma. 1995;12:1-21.

28. Leng L, Metz CN, Fang Y, Xu J, Donnelly S, Baugh J, Delohery T, Chen Y, Mitchell RA, Bucala R. MIF signal transduction initiated by binding to CD74. J Exp Med. 2003;197:1467-76.

29. Bernhagen J, Krohn R, Lue H, Gregory JL, Zernecke A, Koenen RR, Dewor M, Georgiev I, Schober A, Leng L, et al. MIF is a noncognate ligand of CXC chemokine receptors in inflammatory and atherogenic cell recruitment. Nat Med. 2007;13:587-96.

30. DeLeon-Pennell KY, Iyer RP, Ero OK, Cates CA, Flynn ER, Cannon PL, Jung M Shannon D, Garrett MR, Buchanan W, et al. Periodontal-induced chronic inflammation triggers macrophage secretion of $\mathrm{Cl} 12$ to inhibit fibroblastmediated cardiac wound healing. JCI Insight. 2017;2:14. 
31. Kim MO, Suh HS, Brosnan CF, Lee SC. Regulation of RANTES/CCL5 expression in human astrocytes by interleukin-1 and interferon-beta. J Neurochem. 2004; 90:297-308.

32. Nakamichi K, Saiki M, Sawada M, Takayama-Ito M, Yamamuro Y, Morimoto K, Kurane I. Rabies virus-induced activation of mitogen-activated protein kinase and NF-kappaB signaling pathways regulates expression of CXC and CC chemokine ligands in microglia. J Virol. 2005;79:11801-12.

33. Tanuma N, Sakuma H, Sasaki A, Matsumoto Y. Chemokine expression by astrocytes plays a role in microglia/macrophage activation and subsequent neurodegeneration in secondary progressive multiple sclerosis. Acta Neuropathol. 2006;1 12:195-204.

34. Murray PJ, Allen JE, Biswas SK, Fisher EA, Gilroy DW, Goerdt S, Gordon S, Hamilton $J A$, Ivashkiv $L B$, Lawrence $T$, et al. Macrophage activation and polarization: nomenclature and experimental guidelines. Immunity. 2014;41:14-20.

35. Leyton-Jaimes MF, Kahn J, Israelson A. Macrophage migration inhibitory factor: a multifaceted cytokine implicated in multiple neurological diseases. Exp Neurol. 2018;301:83-91.

36. Bacher M, Schrader J, Thompson N, Kuschela K, Gemsa D, Waeber G, Schlegel J. Up-regulation of macrophage migration inhibitory factor gene and protein expression in glial tumor cells during hypoxic and hypoglycemic stress indicates a critical role for angiogenesis in glioblastoma multiforme. Am J Pathol. 2003;162:11-7.

37. An JH, Lee SY, Jeon JY, Cho KG, Kim SU, Lee MA. Identification of gliotropic factors that induce human stem cell migration to malignant tumor. J Proteome Res. 2009:8:2873-81.

38. Benedek G, Meza-Romero R, Jordan K, Keenlyside L, Offner H, Vandenbark AA. HLA-DRalpha1-mMOG-35-55 treatment of experimental autoimmune encephalomyelitis reduces CNS inflammation, enhances M2 macrophage frequency, and promotes neuroprotection. J Neuroinflammation. 2015;12:123.

39. Calandra T, Bernhagen J, Mitchell RA, Bucala R. The macrophage is an important and previously unrecognized source of macrophage migration inhibitory factor. J Exp Med. 1994;179:1895-902.

40. David S, Kroner A. Repertoire of microglial and macrophage responses after spinal cord injury. Nat Rev Neurosci. 2011;12:388-99.

41. Thawer SG, Mawhinney L, Chadwick K, de Chickera SN, Weaver LC, Brown A Dekaban GA. Temporal changes in monocyte and macrophage subsets and microglial macrophages following spinal cord injury in the Lys-Egfp-ki mouse model. J Neuroimmunol. 2013:261:7-20.

42. Shi X, Leng L, Wang T, Wang W, Du X, Li J, McDonald C, Chen Z, Murphy JW, Lolis $\mathrm{E}$, et al. CD44 is the signaling component of the macrophage migration inhibitory factor-CD74 receptor complex. Immunity. 2006;25:595-606.

43. Lue H, Dewor M, Leng L, Bucala R, Bernhagen J. Activation of the JNK signalling pathway by macrophage migration inhibitory factor (MIF) and dependence on CXCR4 and CD74. Cell Signal. 2011;23:135-44.

44. Zhu G, Tang Y, Geng N, Zheng M, Jiang J, Li L, Li K, Lei Z, Chen W, Fan Y, et al. HIF-alpha/MIF and NF-kappaB/L-6 axes contribute to the recruitment of CD11b+Gr-1+ myeloid cells in hypoxic microenvironment of HNSCC. Neoplasia. 2014;16:168-79.

45. Ishida Y, Kimura A, Kuninaka Y, Inui M, Matsushima K, Mukaida N, Kondo T. Pivotal role of the CCL5/CCR5 interaction for recruitment of endothelial progenitor cells in mouse wound healing. J Clin Invest. 2012;122:711-21.

46. Keophiphath M, Rouault C, Divoux A, Clement K, Lacasa D. CCL5 promotes macrophage recruitment and survival in human adipose tissue. Arterioscler Thromb Vasc Biol. 2010;30:39-45.

47. Keepers TR, Gross LK, Obrig TG. Monocyte chemoattractant protein 1, macrophage inflammatory protein 1 alpha, and RANTES recruit macrophages to the kidney in a mouse model of hemolytic-uremic syndrome. Infect Immun. 2007;75:1229-36

48. Liou JT, Yuan HB, Mao CC, Lai YS, Day YJ. Absence of C-C motif chemokine ligand 5 in mice leads to decreased local macrophage recruitment and behavioral hypersensitivity in a murine neuropathic pain model. Pain. 2012; 153:1283-91.

49. Lee CM, Peng HH, Yang P, Liou JT, Liao CC, Day YJ. C-C chemokine ligand-5 is critical for facilitating macrophage infiltration in the early phase of liver ischemia/reperfusion injury. Sci Rep. 2017;7:3698.

50. Zhang B, Gensel JC. Is neuroinflammation in the injured spinal cord different than in the brain? Examining intrinsic differences between the brain and spinal cord. Exp Neurol. 2014;258:112-20.

51. Si Q, Kim MO, Zhao ML, Landau NR, Goldstein H, Lee S. Vpr- and Nefdependent induction of RANTES/CCL5 in microglial cells. Virology. 2002; 301:342-53.

Ready to submit your research? Choose BMC and benefit from:

- fast, convenient online submission

- thorough peer review by experienced researchers in your field

- rapid publication on acceptance

- support for research data, including large and complex data types

- gold Open Access which fosters wider collaboration and increased citations

- maximum visibility for your research: over $100 \mathrm{M}$ website views per year

At BMC, research is always in progress.

Learn more biomedcentral.com/submissions 